Received: 08 June 2021 :: Accepted: 21 June 2021 :: Published: 30 June 2021

\title{
PENERAPAN GIZI SEIMBANG SELAMA MASA PUASA DI DESA PERBARAKAN, KECAMATAN LUBUK PAKAM TAHUN 2021
}

\section{Delita Br Panjaitan', Raisha Octavariny², Sri Melda Br Bangun², Anggi Isnani Parinduri $^{2}$, Ade Julfiani Ritonga ${ }^{2}$}

\author{
${ }^{1}$ Progaran Studi Gizi, Institut Kesehatan Medistra Lubuk Pakam \\ ${ }^{2}$ Program Studi Kesehatan Masyarakat, Institut Kesehatan Medistra Lubuk Pakam
Jln. Sudirman No.38 Lubuk Pakam, Kabupaten Deli Serdang, Sumatera Utara - Indonesia
*email korespondensi author: delita.lita16@gmail.com

DOI $10.35451 /$ jpk.v1i1.733

\begin{abstract}
Abstrak
Sebagaimana kewajiban yang dijalankan oleh umat Islam, berpuasa merupakan golongan partial fasting yaitu puasa yang dijalankan segala berkala. Salah satu indikasi puasa dikategorikan baik apabila diawali dengan berbuka, mengakhirkan sahur, berhenti makan sebelum kenyang. Selama masa puasa sangat dianjurkan untuk tetap menerapkan gizi seimbang. Selain kandungan gizinya, bentuk/jenis makanan yang disajikan juga perlu diperhatikan sehingga pelaksanaan puasa berjalan dengan baik dan tanpa menimbulkan masalah kesehatan terkhusus pada organ lambung. Kegiatan PKM ini dilaksanakan dengan tujuan untuk meningkatkan pengetahuan dan pemahaman dalam penerapan gizi seimbang selama menjalankan ibadah puasa dengan sasaran ibu-ibu PKK yang berada di Desa Perbarakan, Kecamatan Lubuk Pakam. Dilakukan pre dan post tes untuk melihat apakah ada peningkatan pemahaman akan gizi seimbang. Kegiatan dilakukan dengan memberikan informasi berupa penyuluhan gizi seimbang serta tips bagaimana tata laksana gizi seimbang di keluarga. Waktu pelaksanaan kegiatan adalah selama 1 minggu dengan jumlah pertemuan sebanyak empat kali. Setelah penyuluhan dilakukan sangat diharapkan adanya peningkatan pengetahuan akan gizi seimbang yang nantinya akan diterapkan di rumah masing-masing selama masa puasa. Selama berlangsungnya penyuluhan, tim pelaksana juga menyediakan alat peraga berupa food model dan leaflet. Hasil yang diperoleh dapat diamati pada gambar grafik yang akan ditampilkan dimana ada peningkatan pemahaman akan gizi seimbang. Selain itu, dengan adanya alat peraga juga membantu mempermudah penyampaian materi gizi seimbang.
\end{abstract}

Kata Kunci: Gizi Seimbang; Puasa; Penyuluhan

\begin{abstract}
As an obligation carried out by Muslims, fasting is a partial fasting group, namely fasting that is carried out periodically. One indication of fasting is categorized as good if it begins with breaking the fast, ending sahur, stopping eating before being full. During the fasting period, it is highly recommended to maintain a balanced diet. In addition to the nutritional content, the form / type of food served also needs to be considered so that the implementation of fasting goes well and without causing health problems, especially in the stomach organ. This PKM activity was carried out with the aim of increasing knowledge and understanding in the application of balanced nutrition during fasting worship with the target of PKK mothers in Perbarakan Village, Lubuk Pakam District. Pre and post tests were conducted to see if there was an increase in understanding of balanced nutrition. Activities are carried out by providing information in the form of balanced nutrition counseling and tips on how to manage balanced nutrition in the family. The implementation time of the activity is 1 week with a total of four meetings. After the counseling is done, it is hoped that there will be an increase in knowledge about balanced nutrition which will later be applied in their respective homes during the fasting period. During the extension, the implementation team also provided props in the form of food models and leaflets. The results obtained can be observed in the graphic images that will be displayed where there is an increased understanding of balanced nutrition. In addition, the existence of teaching aids also helps facilitate the delivery of balanced nutrition material.
\end{abstract}

Keywords: Balanced Nutrition; Fasting; Counseling 
Received: 08 June 2021 :: Accepted: 21 June 2021 :: Published: 30 June 2021

\section{Pendahuluan}

Gizi seimbang merupakan suatu proses organisme dalam menggunakan makanan yang dikonsumsi secara normal melalui proses digesti, absorbsi, transportasi, penyimpanan, metabolisme serta pengeluaran zat-zat yang sudah tidak lagi diperlukan oleh tubuh (Susilowati, 2016)

Sebagai sumber energy, pertumbuhan badan, pemelihara jaringan dalam tubuh, mengganti sel rusak dan meregenerasi sel, mengatur metabolism tubuh, serta berperan dalam meningkatkan imun tubuh dalam menangkal radikal bebas (Jauhari, 2015).

Puasa di Bulan Ramadhan merupakan salah satu kewajiban bagi umat Muslim seluruh dunia. Satu bulan penuh lamanya umat Muslim menjalankan puasa secara langsung. Perubahan pola makan yang terjadi sangat mempengaruhi metabolism dalam tubuh. Pencegahan kekurangan gizi yang mungkin terjadi selama menjalankan puasa perlu adanya pengetahuan gizi seimbang dan penerapannya (Darti, 2019).

Selama puasa ramadhan penurunan asupan zat gizi dapat dipengaruhi oleh penurunan frekuensi dan jumlah makan, penurunan metabolisme lemak dalam tubuh, dan perubahan hormonal yang menyebabkan perubahan selera makan selama malam hari. Asupan makanan saat puasa ramadhan dilakukan saat berbuka puasa, malam hari, dan sahur. Meskipun frekuensi makan dibatasi, kualitas makanan harus ditingkatkan guna memenuhi kebutuhan zat gizi sehari (Nurjanah, 2017). Pola makan selama ramadhan mengalami perubahan, diantaranya berupa praktek makan yang cenderung dilakukan dengan porsi besar sesaat setelah matahari terbenam dan porsi kecil sesaat sebelum matahari terbit (Trepanowski dan Bloomer 2010).

Gizi seimbang merupakan suatu susunan pangan sehari-hari dengan jenis dan jumlah yang sesuai kebutuhan tubuh serta tetap memperhatikan prinsip keberagaman pangan, aktivitas fisik, PHBS serta mempertahankan berat badan normal guna mencegah permasalahan gizi.

Kurangnya jumlah asupan zat gizi dapat menyebabkan seseorang mengalami defisit kebutuhan tubuhnya. Konsekuensi yang akan muncul salah satunya adalah munculnya penyakit infeksi yang mana bila terjadi sudah pasti akan memperburuk kondisi gizi. Pengetahuan gizi seimbang merupakan pengetahuan tentang makanan dan zat, sumber zat gizi yang ada pada makanan serta makanan yang sifatnya aman dikonsumsi dan tidak menyebabkan munculnya penyakit (Laswanti, 2017)
Keinginan untuk memenuhi asupan gizi dengan makan akan muncul secara naluriah. Ukuran terpenuhinya kebutuhan akan pangan dapat dinyatakan dengan kondisi tidak lapar. Setiap harinya seluruh individu akan melakukan aktivitas fisik sehingga energi jelas sangat dibutuhkan (Murtie, 2014)

Memperhatikan asupan gizi seimbang akan me,pertahankan kondisi individu selama berpuasa. Mulai dari asupan zat gizi makro hingga gizi mikro akan sangat mempengaruhi kondisi tubuh. Kualitas tubuh secara maksimal selama puasa akan dicapai dengan konsumsi gizi seimbang.

\section{Metode}

Kegiatan pengabdian masyarakat ini dilakukan di Desa Perbarakan dengan membentuk tim kerja dimana tim tersebut melakukan koordinasi pada pihak PKK Desa dalam perencanaan kegiatan penyuluhan gizi seimbang. Media yang digunakan adalah leaflet serta alat peraga berupa food model. Penyuluhan dilakukan pada 12 sasaran yang terdiri dari ibu PKK yang ada di desa tersebut.

\section{Hasil dan Pembahasan}

Kegiatan penyuluhan penerapan gizi selama masa puasa telah selesai dilaksanakan pada tanggal 16 April 2021 dengan sasaran peserta kegiatan ini adalah ibu-ibu PKK di Desa Perbarakan. Kegiatan pengabdian masyarakat ini dilakukan dengan tujuan menambah wawasan keluarga khususnya ibu-ibu dalam memperhatikan asupan gizi seimbang untuk mengoptimalkan tubuh selama berpuasa.

Pelaksanaan pengabdian masyarat ini diawalai dengan pemaparan tujuan kegiatan, kemudian dilanjutkan penyampaian materi oleh narasumber yang meliputi gizi seimbang selama berpuas, memberikan contoh menu gizi seimbang dengan alat bantu food model agar peserta mudah memahami takaran ukuran rumah tangga. Setelah pemaparan materi selesai, dilakukan sesi tanya jawab untuk mengevaluasi pemahaman peserta mengenai materi yang disampaikan, kemudian tim mebagikan leaflet kepada peserta sebagai salah satu media yang digunakan pada pelaksanaan pengabdian masyarakat dan sebagai bahan bacaan apabila peserta kurang memahami dalam penyampaian ataupun lupa sehingga peserta dapat membacanya kembali.

Penutupan, pada tahapan ini disampaikan ucapan terima kasih pelaksana kepada peserta yang sudah berpartisipasi sekaligus mengakhiri kegiatan penyuluhan. 
Received: 08 June 2021 :: Accepted: 21 June 2021 :: Published: 30 June 2021

\section{Kesimpulan}

\section{Kegiatan}

pengabdian

masyarakat melalui penyuluhan sangat bermafaat bagi peserta yang dapat dilihat dari antusiasme peserta mengikuti kegiatan dari awal sampai akhir kegiatan ini dilaksanakan dan para peserta berharap akan adanya kegiatan-kegiatan bermanfaat lainnya dalam bidang kesehatan di Desa mereka.

\section{Ucapan Terima Kasih}

Pengabdian masyarakat ini terlaksana atas kerjasama dan komitmen bersama antara tim pelaksana PKM serta para peserta yang telah terlibat dalam terselenggaranya kegian pengabdian masyarakat sehingga tujuan bersama dapat tecapai.

\section{Daftar Pustaka}

Darti. (2019, Juni 8). Gizi Seimbang di Bulan Ramadhan. RSD Gunung Jati. Indonesia, M. K. (2014). Pedoman Gizi Seimbang. Peraturan Menteri Kesehatan Republik Indonesia.

Jauhari, A. (2015). Dasar-dasar IImu Gizi. Yogyakarta. Jaya IImu

Laswanti, D. T. (2017). Masalah Gizi dan Peran Gizi Seimbang. Agrotech.

Murtie. (2014). All About Kesehatan Anak. Yogyakarta.

Trepanowski, J.F., Bloomer, R.J., 2010. The impact of religious fasting on human health. Nutr J, vol. 9, no. 1, pp 57-66. 